\title{
Correlation between field triage criteria and the injury severity score of trauma patients in a French inclusive regional trauma system
}

Arnaud Cassignol ${ }^{1 *}$, Julien Marmin², Jean Cotte ${ }^{3}$, Mickael Cardinale $^{3}$, Julien Bordes ${ }^{3}$, Vanessa Pauly ${ }^{4}$, François Kerbaul ${ }^{5,6}$, Didier Demory ${ }^{7}$ and Eric Meaudre ${ }^{3}$

\begin{abstract}
Background: In France, the pre-hospital field triage of trauma patients is currently based on the Vittel criteria algorithm. This algorithm was originally created in 2002 before the stratification of trauma centers and, at the national level, has not been revised since. This could be responsible for the overtriage of trauma patients in Level I Trauma Centers. The principal aim of this study was to evaluate the correlation between each Vittel field triage criterion and trauma patients' Injury Severity Score.

Methods: Our Level I Trauma Center receives an average of 300 trauma patients per year. Demographic and physiological data, along with the entire trauma patient management process and Vittel field triage criteria, are recorded in a local trauma registry. The Abbreviated Injury Scale (AIS) and Injury Severity Score (ISS) are calculated after a complete assessment of the trauma victim during their in-hospital management. Results were concerned with the presence of an ISS of greater than 15, which defined a major trauma patient; mortality within 30 days; and admission to the intensive care unit. This study is a registry analysis from January 2013 to September 2017.

Results: Of the 1373 patients in the registry, 1151 were included in the analysis with a mean age of 43 years ( \pm 19) and a median ISS of $13(\mathrm{IQR}=5-22)$, where $887(77 \%)$ were male. Nine of the 24 Vittel criteria were associated with an ISS > 15. In a multivariate analysis, no criterion related to kinetic elements was significantly correlated with an ISS > 15, mortality within 30 days, or admission to intensive care. Three algorithm categories were predictive of a major trauma patient (ISS > 15): physiological variables, pre-hospital resuscitation, and physical injuries, while kinetic elements were not.

Conclusions: Criteria related to physiological variables, pre-hospital resuscitation, and physical injuries are the most relevant to predicting the severity of a trauma patient's condition. A revision of the VCA could potentially have beneficial effects on the over and undertriage phenomena, which constitute ongoing medical and financial concerns.
\end{abstract}

Keywords: Field triage, Vittel criteria, Algorithm, ISS, Mortality, Intensive care unit

\footnotetext{
* Correspondence: acassignol@yahoo.fr

'SMUR Department, Sainte-Musse Public Hospital, 83100 Toulon, cedex 9,

France

Full list of author information is available at the end of the article
}

(C) The Author(s). 2019 Open Access This article is distributed under the terms of the Creative Commons Attribution 4.0 International License (http://creativecommons.org/licenses/by/4.0/), which permits unrestricted use, distribution, and reproduction in any medium, provided you give appropriate credit to the original author(s) and the source, provide a link to the Creative Commons license, and indicate if changes were made. The Creative Commons Public Domain Dedication waiver (http://creativecommons.org/publicdomain/zero/1.0/) applies to the data made available in this article, unless otherwise stated. 


\section{Background}

The goal of pre-hospital triage is to refer an injured patient to the most appropriate center according to their current clinical status. Several studies have proven that referring trauma patients to specialized Trauma Centers (TCs) reduces mortality $[1,2]$. The benefits are even greater when patients are in critical condition [3, 4]. Field triage algorithms were initially developed in the United States of America [5], and these provided the basis for the decision of French emergency physicians to create their own triage algorithm for the trauma system in France. In 2002, they developed the Vittel Criteria Algorithm (VCA) for pre-hospital physicians in order to quickly screen possible major trauma patients and refer them to appropriate TCs [6]. However, there was not yet any TC stratification in France at this time, and as time passed, this change resulted in an overtriage of trauma patients in Level I TCs. Pre-hospital overtriage increases costs, patients' geographical constraints, and overcrowding in referral centers [7].

Consequently, overtriage causes trauma teams to commit valuable resources to patients that do not actually require the care of a Level I TC. This could then lead to an upsurge of patient undertriage in Level I TCs, which increases the morbidity and mortality rates of the most critically ill patients. A few studies have assessed the Vittel criteria, and most of them conclude that there is more overtriage than undertriage [8-10].

The VCA comprises 24 different criteria divided into five categories: 3 in physiological variables, 6 in kinetic elements, 7 in physical injuries, 3 in pre-hospital resuscitation, and 5 in special considerations (Fig. 1). Pre-hospital resuscitation criteria have been added to the French algorithm due to the rise of pre-hospital emergency care. According to several studies, a good triage algorithm should result in an undertriage of less than $5 \%$ with an overtriage of 25$50 \%[11,12]$. In hospitals, major trauma is usually defined as an Injury Severity Score (ISS) of greater than 15 (gold standard) [13]. This score can only be calculated after a complete evaluation and whole-body CT-scan of the trauma patient in hospital [14]. An appropriate pre-hospital triage protocol would be to direct a major trauma patient (with ISS > 15) to a Level I TC.

Our main objective was to study the correlation between the different pre-hospital field triage criteria and the probability of an ISS of greater than 15 . Our secondary objectives were to study their association with mortalities within 30 days and admission to the Intensive Care Unit (ICU).

\section{Methods}

We performed a monocentric registry analysis study in the Sainte Anne Military Hospital of Toulon (South East of France), a Level I TC, which has all the necessary medical and surgical resources for treating any type of traumatic injury. It receives an average of 300 trauma patients per year. A registry of trauma patients in the Sainte Anne hospital in Toulon was started in 2013 to collect data prospectively in accordance with the Utstein-Style guidelines [15]. Raw data were collected prospectively on paper by physicians and were entered into an electronic database. A clinical research assistant regularly verifies the integrity and completeness of the data and collects patient outcomes upon discharge. All patients in the registry from January 2013 to September 2017 were included in the study so long as severe trauma was suspected in the pre-hospital setting according to the Vittel field triage criteria (Fig. 1).

Both demographic and physiological data, along with the entire trauma patient management process (from the scene of the accident to hospital discharge) and Vittel field triage criteria, were recorded in this local trauma registry. The presence of even a single Vittel criterion, which was recorded by the pre-hospital physician in the field, justified the referral of a trauma patient to our TC. There was no severity grading in our criteria. This study was approved by the Sainte Anne Hospital Institutional Review Board (IRB 00011873-2019 - 02).

Our trauma registry consisted of: i) demographic data (age, gender), ii) type of trauma and mechanism of injury; iii) pre-hospital clinical examination results (Glasgow coma scale, heart rate, systolic blood pressure, respiratory rate, oxygen saturation), and iv) pre-hospital resuscitation (mechanical ventilation, catecholamine administration, and fluid loading). When a trauma patient was referred to our major trauma care unit, a whole-body CT-scan was systematically performed. Subsequently, both the Abbreviated Injury Scale (AIS) and Injury Severity Score (ISS) were established after a complete assessment of the trauma victim. The ISS is derived from the AIS which concerns itself with six regions of the human body (head and neck, face, thorax, abdomen, limbs, external surface) [16]. The ISS is then calculated by summing the squares of the three highest AIS ratings. This ISS is then rated from 1 to 75 . In common standards, if an injury is rated AIS 6 (fatal), the ISS is arbitrarily set at 75. Our primary outcome was defined by an ISS of greater than 15 (major trauma).

Descriptive statistics included frequencies and percentages for categorical variables, and the mean (SD) or median (IQR) for continuous variables. The association between the 24 field triage criteria and an ISS of greater than 15, a 30-day mortality, and admission to the ICU was analyzed via unifactorial logistic regression. All criteria presenting a $p$-value $<0.20$ were systematically included in a multifactorial (adjusted) logistic regression model, where $p<0.05$ was significant. The results were expressed as an Odds Ratio (OR) with associated confidence intervals $(95 \% \mathrm{CI})$.

The predictive performance (comprising: Sensitivity (Se), Specificity (Sp), Positive (PPV) and Negative (NPV) Predictive Value, Positive (PLR) and Negative (NLR) Likelihood 


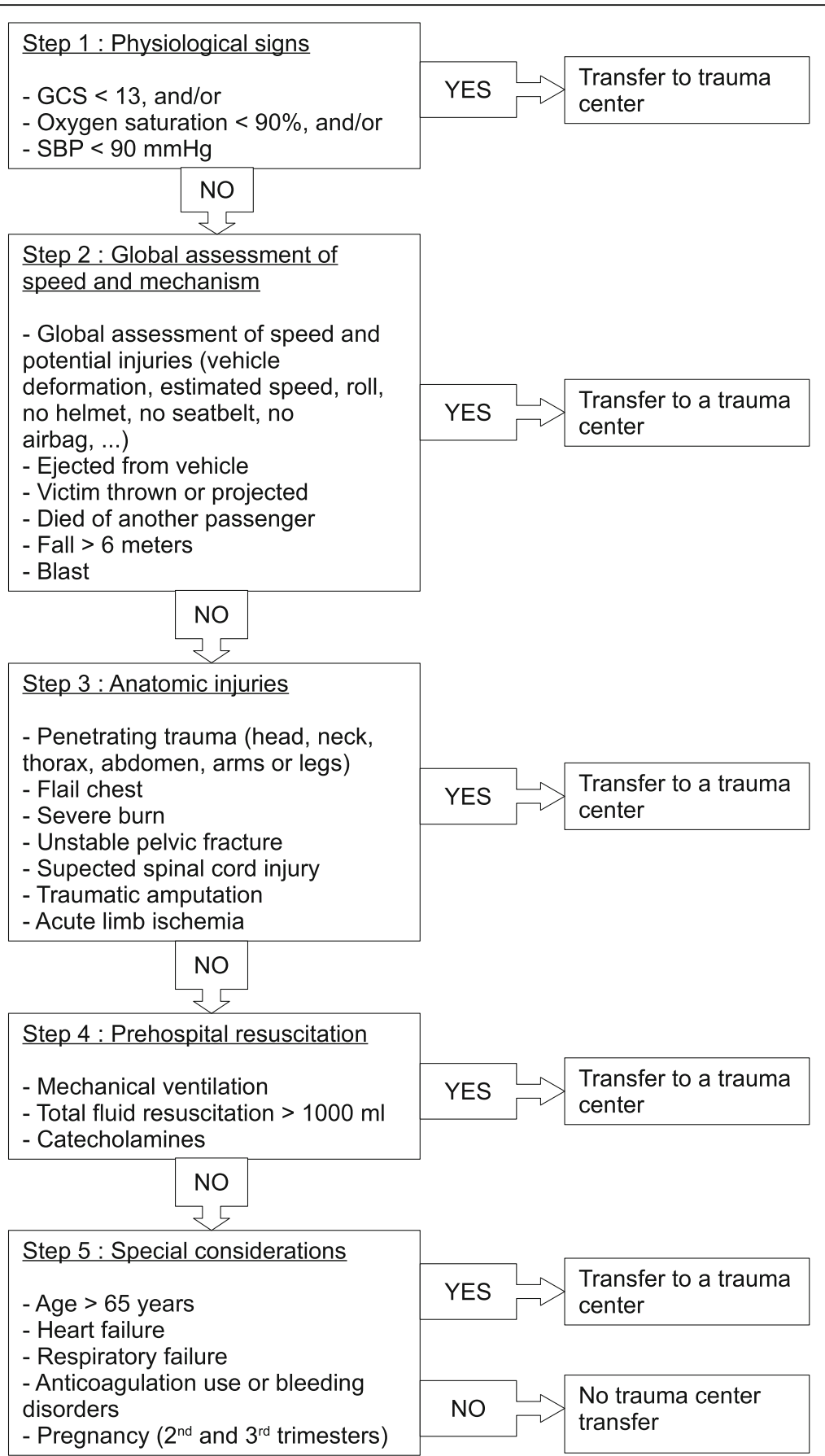

Fig. 1 Vittel Criteria Algorithm for French field triage. GCS: Glasgow Coma Scale; SBP: Systolic Blood Pressure

Ratios, and Youden index) of each of the five VCA categories were calculated.

A Receiver Operating Characteristic (ROC) curve was used in order to assess the VCA predictive performance of having an ISS $>15$. The completion of these statistical tests led to the formation of two alternative algorithms. The first was made by eliminating the category with the least predictive performance (i.e. a 4-step algorithm), whereas the second eliminated the two lowest categories (i.e. a 3step algorithm). Finally, we compared the complete VCA (5 step-algorithm) versus our two alternative 4 and 3-step algorithms in accordance with the method of Delong et al. [17].

The statistical software SPSSv20 and MedCalc V14.8.1 were used for data acquisition and analysis. The significance was set at $p<0.05$. 


\section{Results}

Between January 2013 and September 2017, 1373 trauma patients were added to the TC's registry, of which 222 (16\%) were excluded from the study due to either missing data (184 patients) or loss to follow up (38 patients) (Fig. 2). This left 1151 (84\%) includable patients that were analyzed in the study. On average, each patient met 2 to 3 field triage criteria. Twenty-seven (2\%) patients did not meet any field triage criteria. The main characteristics of the study population are listed in Table 1.

\section{Primary results}

In our Level I TC, 524 patients (46\%) presented an ISS of greater than 15 . The correlation between the field triage criteria and an ISS > 15 is reported in Tables 2 and 3 (univariate and multivariate analysis, respectively). Nine field triage criteria were significantly associated with an ISS of greater than 15 in multivariate analysis $(p<0.05)$. Table 4 includes the predictive performance of each category of the VCA regarding an ISS of greater than 15. Physiological variables (1st category) and pre-hospital resuscitation (4th category) had greater predictive performance concerning an ISS > 15. However, kinetic elements (2nd category) had the poorest performance. ROC curve comparisons did not find any significant differences between the VCA and our 3 and 4-step alternative algorithms (Fig. 3 and Table 5).

\section{Secondary results}

Six hundred and sixty patients $(57 \%)$ were admitted to the ICU. The 30 -day mortality rate was $8 \%$ of the entire study population, and $16 \%$ of trauma patients with an ISS $>15$. In a multivariate analysis, 7 and 8 Vittel field triage criteria were significantly associated with the 30 -day mortality rate and ICU admissions, respectively (Table 3). Similarly, physiological variables and pre-hospital resuscitation had the best performances in predicting the 30-day mortality rate and the necessity for admission to an ICU. Kinetic elements had the poorest predictive performance (Table 4). The analysis of the VCA ROC curves revealed an AUROC of $0.87(0.85-0.89)$ for predicting a death within 30 days and an AUROC of $0.74(0.71-0.76)$ for predicting an admission to the ICU.

\section{Discussion}

Of the 24 Vittel field triage criteria, 9 were associated with the probability of having an ISS of greater than 15 . Two categories of the VCA were strongly predictive of a major trauma patient (ISS > 15): physiological variables and prehospital resuscitation. Physical injuries also constituted a good indicator for predicting an ISS of greater than 15, whereas kinetic elements were not. The comparison of our two alternative algorithms' ROC curves with the VCA did not reveal any differences in predicting an ISS of greater than 15. Regarding our secondary results, 7 and 8 criteria were associated with a risk of 30-day mortality and ICU admission, respectively. The most relevant categories for predicting the risk of 30-day mortality and ICU admission were also physiological variables, pre-hospital resuscitation, and physical injuries, while kinetic elements did not appear to be significant.

In general, major trauma patients (ISS > 15) usually meet several field triage criteria. In our study, major trauma patients mainly presented kinetic elements, in combination with other algorithmic categories (physiological variables, pre-hospital resuscitation, or physical injuries). However, the kinetic elements category of field

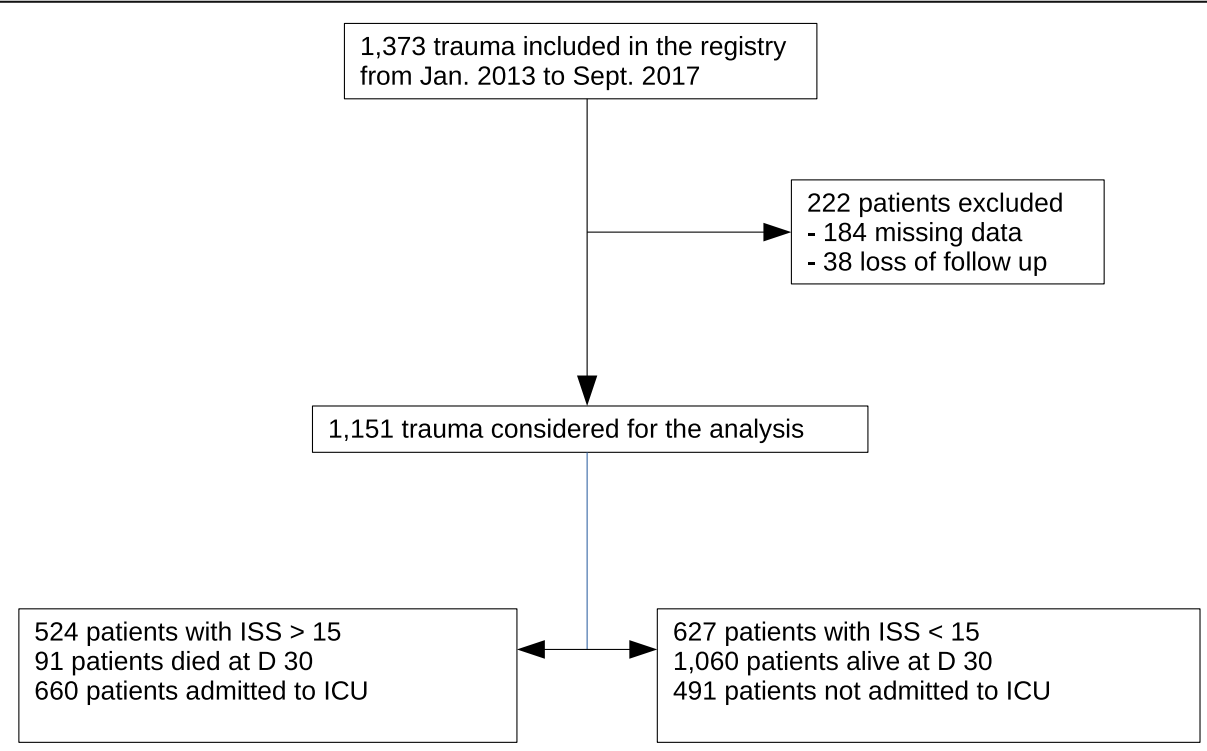

Fig. 2 Study population flowchart. ISS: Injury Severity Score, D: Day, ICU: Intensive Care Unit 
Table 1 Study population characteristics ( $n=1151$ patients)

\begin{tabular}{|c|c|}
\hline Characteristic & Value \\
\hline Sex: Male, $n(\%)$ & $887(77)$ \\
\hline Age: mean (SD) & $43( \pm 19)$ \\
\hline \multicolumn{2}{|l|}{ Mechanism of injury } \\
\hline Blunt, $n(\%)$ & $1063(92)$ \\
\hline Penetrating, $n(\%)$ & $88(8)$ \\
\hline \multicolumn{2}{|l|}{ Type of trauma } \\
\hline Car crash, $n(\%)$ & $263(23)$ \\
\hline Motorcycle, $n(\%)$ & $457(40)$ \\
\hline Pedestrian, $n$ (\%) & $74(6)$ \\
\hline Fall, $n(\%)$ & $228(20)$ \\
\hline Gunshot, $n(\%)$ & $48(4)$ \\
\hline Stab wound, $n(\%)$ & $34(3)$ \\
\hline Other, $n(\%)$ & $47(4)$ \\
\hline \multicolumn{2}{|l|}{ Pre-hospital physiological variables: median (IQR) } \\
\hline Glasgow coma scale & $15(13-15)$ \\
\hline Heart rate, beats/min & $86(75-100)$ \\
\hline Systolic arterial blood pressure, $\mathrm{mm} \mathrm{Hg}$ & $120(108-137)$ \\
\hline Peripheral oxygen saturation, $\%$ & $99(97-100)$ \\
\hline \multicolumn{2}{|l|}{ Pre-hospital resuscitation } \\
\hline Mechanical Ventilation, $n$ (\%) & $197(17)$ \\
\hline Catecholamine administration, $n(\%)$ & $106(9)$ \\
\hline Total fluid loading, mL: median (IQR) & $250(0-500)$ \\
\hline MGAP score: median (IQR) & $27(22-28)$ \\
\hline \multicolumn{2}{|l|}{ MGAP category, $n(\%)$} \\
\hline $3-17^{a}$ & $133(12)$ \\
\hline $18-22^{b}$ & $201(18)$ \\
\hline $23-29^{c}$ & $817(71)$ \\
\hline ISS: median (IQR) & $13(5-22)$ \\
\hline ISS $\geq 15, n(\%)$ & $524(46)$ \\
\hline \multicolumn{2}{|l|}{ Field triage criterion categories, $n(\%)$} \\
\hline Physiological variables & $420(15)$ \\
\hline Kinetic elements & $1328(48)$ \\
\hline Physical injuries & $383(14)$ \\
\hline Pre-hospital resuscitation & $373(13.5)$ \\
\hline Special considerations & $260(9.5)$ \\
\hline ICU admission during the hospital stay, $n(\%)$ & $660(57)$ \\
\hline In-hospital mortality within 30 days, $n$ (\%) & $91(8)$ \\
\hline
\end{tabular}

MGAP score: Mechanism, Glasgow coma scale, Age, systolic blood Pressure ${ }^{a}$ High risk of mortality; ${ }^{b}$ intermediate risk of mortality; ${ }^{c}$ low risk of mortality ISS Injury Severity Score, ICU Intensive Care Unit

triage may not be the most relevant for identifying patients who will require the resources of a Level I TC [18]. What's more, we demonstrated that kinetic elements were not significant indicators of patients with an ISS of greater than 15 . In our study, the elimination of the criteria related to kinetic elements (2nd category; 4-step algorithm) and/or special considerations (5th category; 3-step algorithm) did not improve the performance of the algorithm in predicting an ISS $>15$ in trauma patients (no significant differences between AUROCs). Our results highlighted the limitations of some of the components of the current triage algorithm in defining severe trauma. Indeed, it could be interesting to further assess the effect of score adjustments on the pre-hospital misclassification of trauma patients.

In their study, Hamada et al. also found a weak association between the ISS and kinetic elements criteria (PLR = $0.9, \mathrm{NLR}=1.2$ ) [9], whose poor predictive performance was also underlined by the American College of Surgeons Committee On Trauma (ACSCOT) in 2006. In fact, the revision of American field triage algorithms led to the modification of the kinetic elements' category (i.e. the removal of several criteria such as the initial speed, vehicle deformity, and the extrication duration). Lerner et al. (2011) demonstrated that a revision of their current algorithm significantly reduced triage errors by $11 \%$ ( $34 \%$ in 1999 versus $23 \%$ in 2006). As was to be expected, their reduction in overtriage had the subsequent effect of a small increase in the number undertriage patients [19].

The relevance of field triage criteria is inextricably linked to the nature and organization of the associated trauma system, and the field triage criteria related to physiological variables and pre-hospital resuscitation change over time. Therefore, it would also be interesting to evaluate the relevance of the triage criteria of these two categories as a function of arrival times at the trauma center (more or less than $30 \mathrm{~min}$ of emergency medical transportation). Brown et al. (2011) reported that current physiological variables and physical injuries criteria described within the American national trauma triage protocol are both very specific and predictive of the need of referral to a TC [20]. In a trauma system where TCs are stratified, referring trauma patients exclusively suffering from physiological variables, physical injuries, and/ or pre-hospital resuscitation to Level I TCs and redirecting those presenting only kinetic elements-related criteria toward lower levels (II or III) may reduce triage errors [21].

In hospitals, the Injury Severity Score is the most frequently used indicator of trauma severity [22]. This score is mostly based on physical injuries and does not assess the need for specific technical resources. Consequently, the use of composite criteria such as the need for massive transfusions, interventional radiology, neurosurgery, or specialized damage control management (surgical and resuscitative) would be more suitable for referring a trauma patient to a Level I TC [9, 23-25]. In our study, the number of trauma patients admitted to the ICU was greater than the number of patients with an ISS $>15$. Several other pre-hospital triage scores have been developed to assess the severity of 
Table 2 Association between each field triage criterion and risk of an ISS > 15, mortality, or admission to intensive care, respectively, in univariate analysis

\begin{tabular}{|c|c|c|c|c|}
\hline \multirow[t]{2}{*}{ Field triage criteria } & \multirow[t]{2}{*}{$N=2764^{\mathrm{a}}$} & \multicolumn{3}{|c|}{ Evaluation criterion, OR (95\% Cl) } \\
\hline & & ISS $>15$ & 30-day mortality & Admission to ICU \\
\hline GCS score $<13$ & 252 & $7.9(5.6-11.2)$ & $17.2(10.2-29)$ & $8.5(5.6-12.9)$ \\
\hline $\mathrm{SBP}<90 \mathrm{mmHg}$ & 105 & $4.1(2.6-6.5)$ & $3(1.7-5.2)$ & $4.3(2.5-7.3)$ \\
\hline Oxygen saturation $<90 \%$ & 63 & $4.5(2.5-8.3)$ & $9.4(5.3-16.5)$ & $3.3(1.8-6.3)$ \\
\hline Ejection from vehicle & 112 & $0.9(0.6-1.3)$ & $0.9(0.4-1.9)$ & $1.4(0.9-2.1)$ \\
\hline Death of another passenger & 31 & $1.5(0.7-3)$ & $0.8(0.2-3.4)$ & $3.2(1.3-7.8)$ \\
\hline Fall $>6 m$ & 228 & $1.3(1-1.8)$ & $1.5(0.9-2.5)$ & $1.1(0.8-1.4)$ \\
\hline Victim thrown or run over & 253 & $1.1(0.8-1.4)$ & $1.1(0.7-1.9)$ & $1.4(1.02-1.8)$ \\
\hline Global assessment (speed or vehicle deformation) & 701 & $0.9(0.7-1.1)$ & $0.6(0.4-0.8)$ & $1(0.8-1.2)$ \\
\hline Blast & 3 & $0.6(0.1-6.6)$ & NC & $0.4(0.03-4.1)$ \\
\hline Penetrating trauma & 88 & $1.1(0.7-1.6)$ & $3.2(1.8-5.7)$ & $1(0.7-1.6)$ \\
\hline Flail chest & 48 & $9(3.8-21.4)$ & $2.1(0.9-4.8)$ & $3.4(1.6-7)$ \\
\hline Severe burn & 4 & $1.2(0.2-8.5)$ & $3.9(0.4-38)$ & NC \\
\hline Pelvis fracture & 72 & $1.6(1.01-2.6)$ & $0.9(0.3-2.2)$ & $2(1.2-3.4)$ \\
\hline Spinal cord injury & 137 & $2.5(1.7-3.6)$ & $3(1.8-5)$ & $2.7(1.8-4.1)$ \\
\hline Amputation & 17 & $2.9(1.02-8.3)$ & $2.6(0.7-9)$ & $3.5(1.01-12.3)$ \\
\hline Acute limb ischemia & 17 & $1.7(0.7-4.6)$ & $0.7(0.1-5.5)$ & $1.4(0.5-3.7)$ \\
\hline Mechanical ventilation & 197 & $8.9(6-13.4)$ & $13.8(8.6-22.1)$ & $19.1(10-36.5)$ \\
\hline Total fluid resuscitation $>1000 \mathrm{~mL}$ & 70 & $8(4-15.8)$ & $2.9(1.5-5.6)$ & $5.5(2.7-11.1)$ \\
\hline Catecholamine administration & 106 & $10.2(5.7-18.5)$ & $10.4(6.4-16.9)$ & $14.5(6.3-33.4)$ \\
\hline Age $>65$ years & 192 & $2(1.5-2.8)$ & $4.7(3-7.3)$ & $1.5(1.1-2.1)$ \\
\hline Heart failure & 29 & $1.3(0.6-2.7)$ & $2.5(0.9-6.7)$ & $1.4(0.7-3.1)$ \\
\hline Respiratory failure & 4 & $1.2(0.2-8.5)$ & NC & $0.7(0.1-5.3)$ \\
\hline Pregnancy & 4 & $1.2(0.2-8.5)$ & NC & $0.3(0.03-2.4)$ \\
\hline Anticoagulant use or bleeding disorders & 31 & $1.3(0.6-2.6)$ & $3.6(1.5-8.6)$ & $1.4(0.7-2.9)$ \\
\hline
\end{tabular}

GCS Glasgow Coma Scale, SBP Systolic Blood Pressure, ISS Injury Severity Score, OR Odds Ratio, NC Not Calculable

${ }^{\mathrm{a}} \mathrm{N}=$ total number of triage criteria recorded within the study population $(n=1151)$

trauma patients (T-RTS, MGAP score, NTS) [26-28], and while these scores are based on physiological variables and assess the mortality of trauma patients, they do not appear to have a good correlation with the ISS (AUROCs for pre-admission RTS and MGAP were 0.64 and 0.67, respectively) [29].

An age of greater than 65 years old was identified as a risk factor for having an ISS $>15 \quad[\mathrm{OR}=2(1.4-2.8)]$, death within 30 days $[\mathrm{OR}=7.6(4-14.4)]$, and admission to intensive care units $[\mathrm{OR}=1.5(1.02-2.1)]$. These results are in agreement with the literature [30-32]. Particular consideration should be given to these elderly patients, who may not present physiological variables at the time of initial management but whose mortality rate is higher than that of younger patients [33]. Early management by a specialized trauma team could reduce their in-hospital mortality rate [34]. Field triage algorithms constitute a valuable aide for pre-hospital teams but should not be a substitute for clinical common sense. It is important to be aware of all the technical resources provided by TC platforms in order to ensure optimal management and to limit undertriage as much as possible [35]. Further studies are required in order to compile exhaustive and optimal pre-hospital triage criteria or algorithms that can aide physicians in their decisionmaking for appropriate referrals of a trauma patient to their right place at the right time [36].

This study has several limitations. Firstly, this is a monocentric study in a Level I TC. Our study focused on patients who met pre-hospital VCA criteria and were referred to our Level I TC. We did not consider patients who met pre-hospital VCA criteria but, for logistical reasons or initial triage errors, were referred to lower level TCs (II or III), nor those who did not meet at least one VCA criterion during the pre-hospital examination and were directed towards Level II or III TCs yet had an ISS $>15$ after a whole-body CT-scan. Thus, our study does not allow for the assessment of undertriage with 
Table 3 Association between each field triage criterion and risk of an ISS > 15, mortality, or admission to intensive care, respectively, in multivariate analysis

\begin{tabular}{llll}
\hline Field triage criteria & \multicolumn{2}{l}{ Evaluation criterion, OR $(95 \% \mathrm{Cl})$} & \\
\cline { 2 - 3 } & $\mathrm{ISS}>15$ & 30 -day mortality & Admission to ICU \\
\hline GCS score $<13$ & $4.2(2.7-6.6)$ & $7.6(3.6-16.2)$ & $3.4(2.1-5.5)$ \\
$\mathrm{SBP}<90 \mathrm{mmHg}$ & $2.3(1.3-3.9)$ & $\mathrm{NS}$ & $2.3(1.3-4.3)$ \\
Oxygen saturation $<90 \%$ & $\mathrm{NS}$ & $5.6(2.8-11.6)$ & $\mathrm{NS}$ \\
Flail chest & $8(3.2-19.9)$ & $\mathrm{NS}$ & $2.8(1.3-6.1)$ \\
Pelvis fracture & $\mathrm{NS}$ & $\mathrm{NS}$ & $2.2(1.3-3.9)$ \\
Amputation & $3.4(1.1-10.4)$ & $\mathrm{NS}$ & $\mathrm{NS}$ \\
Spinal cord injury & $1.9(1.2-2.9)$ & $\mathrm{NS}$ & $2.1(1.3-3.3)$ \\
Penetrating trauma & $\mathrm{NS}$ & $3.2(1.5-7.1)$ & $\mathrm{NS}$ \\
Mechanical ventilation & $2.2(1.3-3.8)$ & $4.1(1.8-9)$ & $5.9(2.8-12.4)$ \\
Total fluid loading $>1000 \mathrm{~mL}$ & $4(1.9-8.5)$ & $\mathrm{NS}$ & $\mathrm{NS}$ \\
Catecholamine administration & $2(1.01-4.1)$ & $2.3(1.2-4.4)$ & $2.8(1.1-7.1)$ \\
Age $>65$ years & $2(1.4-2.8)$ & $7.6(4-14.4)$ & $1.5(1.02-2.1)$ \\
Anticoagulant use or bleeding disorders & $\mathrm{NS}$ & $3.8(1.1-10.9)$ & $\mathrm{NS}$
\end{tabular}

GCS Glasgow Coma Scale, SBP Systolic Blood Pressure, ISS Injury Severity Score, OR Odds Ratio, NS Not Significant

Table 4 Performance of each category of the Vittel Criteria Algorithm (VCA) in predicting the risk of an ISS > 15, mortality within 30 days, or admission to Intensive Care Unit

\begin{tabular}{|c|c|c|c|c|c|c|c|c|}
\hline \multirow[t]{2}{*}{ VCA Category } & \multirow[t]{2}{*}{$N=2764^{a}$} & \multicolumn{7}{|c|}{ Predictive performance for an ISS > 15} \\
\hline & & Se $\%$ & Sp \% & PPV \% & NPV \% & PLR & NLR & Youden index \\
\hline Step 1: Physiological variables & 420 & 50 & 87 & 77 & 68 & 3,9 & 0.57 & 0.37 \\
\hline Step 2: Kinetic elements & 1328 & 86 & 13 & 45 & 52 & 0.99 & 1.09 & -0.01 \\
\hline Step 3: Physical injuries & 383 & 41 & 77 & 60 & 61 & 1.77 & 0.77 & 0.18 \\
\hline Step 4: Pre-hospital resuscitation & 373 & 41 & 94 & 84 & 65 & 6.19 & 0.68 & 0.34 \\
\hline Step 5: Special considerations & 260 & 23 & 86 & 58 & 57 & 1.27 & 0.85 & 0.09 \\
\hline \multirow[t]{2}{*}{ VCA Category } & $N=2764^{a}$ & \multicolumn{7}{|c|}{ Predictive performance for 30-day mortality } \\
\hline & & Se $\%$ & Sp \% & VPP \% & VPN \% & PLR & NLR & Youden index \\
\hline Step 1: Physiological variables & 420 & 89 & 75 & 24 & 99 & 3.57 & 0.15 & 0.64 \\
\hline Step 2: Kinetic elements & 1328 & 77 & 13 & 7 & 86 & 0.88 & 1.85 & -0.11 \\
\hline Step 3: Physical injuries & 383 & 54 & 71 & 14 & 95 & 1.87 & 0.65 & 0.25 \\
\hline Step 4: Pre-hospital resuscitation & 373 & 73 & 82 & 26 & 97 & 4.11 & 0.33 & 0.55 \\
\hline Step 5: Special considerations & 260 & 45 & 84 & 20 & 95 & 2.8 & 0.7 & 0.29 \\
\hline \multirow[t]{2}{*}{ VCA Category } & $N=2764^{a}$ & \multicolumn{7}{|c|}{ Predictive performance for admission to ICU } \\
\hline & & Se $\%$ & Sp \% & VPP \% & VPN \% & PLR & NLR & Youden index \\
\hline Step 1: Physiological variables & 420 & 45 & 90 & 86 & 55 & 4.49 & 0.61 & 0.35 \\
\hline Step 2: Kinetic elements & 1328 & 86 & 12 & 57 & 39 & 0.98 & 1.19 & -0.02 \\
\hline Step 3: Physical injuries & 383 & 38 & 78 & 70 & 48 & 1.75 & 0.79 & 0.16 \\
\hline Step 4: Pre-hospital resuscitation & 373 & 36 & 97 & 93 & 53 & 10.3 & 0.7 & 0.32 \\
\hline Step 5: Special considerations & 260 & 20 & 85 & 64 & 44 & 1.3 & 0.9 & 0.05 \\
\hline
\end{tabular}



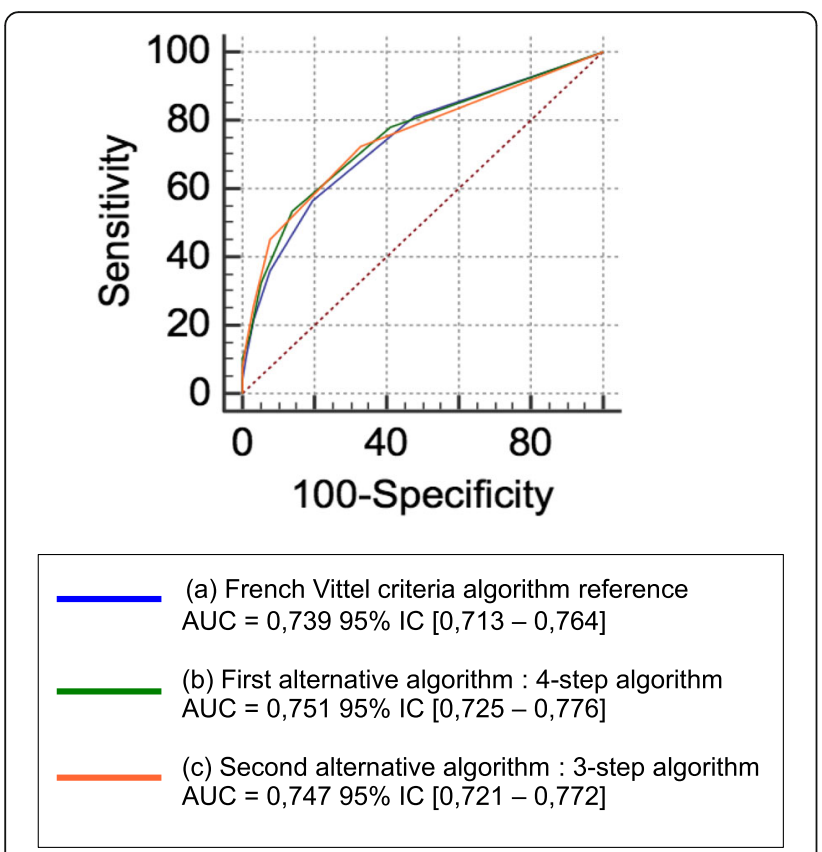

Fig. 3 ROC curves illustrating the predictive performance of each of the 3 algorithms concerning an ISS > 15. (a) French Vittel Criteria Algorithm (VCA) reference (b) First alternative algorithm, a 4-step algorithm: VCA without kinetic elements (2nd category) (c) Second alternative algorithm, a 3-step algorithm: VCA without kinetic elements (2nd category) or special considerations (5th category)

VCA use. Secondly, our study did not allow us to determine whether the decision of the emergency response services or initial physician was only made based on VCA criteria, nor whether the algorithm was used correctly or not. Thirdly, a large number of patients were excluded $(n=222)$ due to either a lack of essential data in the registry concerning pre-admission and/or hospital stay $(n=184)$, or loss to follow-up due to transfer to another hospital $(n=38)$.

\section{Conclusion}

Numerous criteria are used by field triage algorithms to evaluate trauma patients. Each criterion of the VCA has a more or less powerful association with the risk of having an ISS of greater than 15. Criteria related to

Table 5 Comparison between the predictive performance of the Vittel Criteria Algorithm (VCA) for an ISS > 15 and of our two alternative algorithms

\begin{tabular}{llll}
\hline $\begin{array}{l}\text { Pre-hospital field } \\
\text { triage algorithms }\end{array}$ & $\begin{array}{l}\text { AUC } \\
\text { difference }\end{array}$ & $95 \% \mathrm{Cl}$ & $p$ value \\
\hline VCA vs. 4-step algorithm & 0.012 & $-0.004-0.028$ & 0.15 \\
VCA vs. 3-step algorithm & 0.008 & $-0.012-0.029$ & 0.43 \\
4-step algorithm vs. & 0.004 & $-0.009-0.016$ & 0.59 \\
3-step algorithm & & & \\
\hline
\end{tabular}

AUC Area Under Curve

VCA Vittel Criteria Algorithm physiological variables, pre-hospital resuscitation, and physical injuries are the most relevant to predicting the severity of trauma. Criteria related to kinetic elements (in particular those related to vehicle deformation, estimated speed, and ejection from said vehicle) were not significant predictors of trauma severity. A revision of the French triage algorithm, due to its potential effects on the over and the undertriage phenomena, could hold benefits of individual and collective interest, as the misclassification of patients introduces both geographical constraints and medical and financial concerns.

\section{Abbreviations}

AIS: Abbreviated Injury Score; AUC: Area Under Curve; AUROC: Area Under the Receiver Operating Characteristics; Cl: Confidence Intervals; ICU: Intensive Care Unit; IRB: Institutional Review Board; ISS: Injury Severity Score; MGAP score: Mechanism, Glasgow coma scale, Age, arterial Pressure; NTS: New Trauma Score; OR: Odds Ratio; ROC: Receiver Operating Characteristic; RTS: Revised Trauma Score; TC: Trauma Center; T-RTS: Triage-Revised Trauma Score

\section{Acknowledgments}

The authors thank the doctors of the emergency room and intensive care unit of the military hospital of Saint Anne for their work on the registry for major trauma patients.

\section{Authors' contributions}

AC contributed to study design, data analysis and interpretation, literature search, and writing. JM contributed to study design, literature search, and writing. JC, MC, JB, and EM contributed to data collection and critical revision. VP contributed to data analysis and interpretation. FK and DD contributed to critical revision. The final version of the manuscript has been validated by all of the authors.

\section{Funding}

The intercommunal hospital center of Toulon and La Seyne covered expenses and publishing costs but had no role in writing the manuscript, study design, nor collection, analysis, and interpretation of data.

\section{Availability of data and materials}

The data that support the findings of this study are available upon request from the corresponding author, JB, or EM. The data contain information that could compromise research participant privacy and, therefore, are not publicly available.

\section{Ethics approval and consent to participate}

This study was approved by the Sainte Anne Hospital Institutional Review Board (IRB 00011873-2019-02).

\section{Consent for publication}

Given the observational nature of the study, the ethics committee waived the written consent requirements for each patient.

\section{Competing interests}

The authors declare that they have no competing interests.

\footnotetext{
Author details

${ }^{1}$ SMUR Department, Sainte-Musse Public Hospital, 83100 Toulon, cedex 9 France. ${ }^{2}$ Prehospital Emergency Medical Services of Marine Fire Battalion, Marseille, France. ${ }^{3}$ Anesthesia and Intensive Care Department, Sainte-Anne Military Hospital, 83041 Toulon, France. ${ }^{4}$ Public Health and Medical Information Service, Conception Hospital, Aix-Marseille University, 13005 Marseille, France. ${ }^{5}$ SMUR department, Timone Hospital, Aix-Marseille University, 13005 Marseille, France. ${ }^{6}$ MMR MD 2, Aix-Marseille University, Marseille, France. ${ }^{7}$ Clinical research unit, Sainte-Musse Public Hospital, 83100 Toulon, cedex 9, France.
} 
Received: 26 March 2019 Accepted: 26 July 2019

Published online: 05 August 2019

\section{References}

1. Cameron PA, Gabbe BJ, Smith K, Mitra B. Triaging the right patient to the right place in the shortest time. Br J Anaesth. 2014;113(2):226-33.

2. Yeguiayan J-M, Yap A, Freysz M, Garrigue D, Jacquot C, Martin C, et al. Impact of whole-body computed tomography on mortality and surgical management of severe blunt trauma. Crit Care. 2012;16(3):R101.

3. MacKenzie EJ, Rivara FP, Jurkovich GJ, Nathens AB, Frey KP, Egleston BL, et al. A national evaluation of the effect of trauma-center care on mortality. N Engl J Med. 2006;354(4):366-78.

4. Nathens AB, Brunet FP, Maier RV. Development of trauma systems and effect on outcomes after injury. Lancet. 2004;363(9423):1794-801.

5. Hospital and prehospital resources for optimal care of the injured patient Committee on Trauma of the American College of Surgeons. Bull Am Coll Surg. 1986;71(10):4-23.

6. Riou B, Thicoipe M, Atain-Kouadio P. Comment évaluer la gravité? SAMU de France. Actualités en réanimation pré-hospitalière: le traumatisé grave. Paris: SFEM éditions. Vittel. 2002. p. 115-28.

7. Hornez E, Maurin O, Mayet A, Monchal T, Gonzalez F, Kerebel D. French prehospital trauma triage criteria: does the "pre-hospital resuscitation" criterion provide additional benefit in triage? World J Crit Care Med. 2014;3(3):68-73.

8. Babaud J, Ridereau-Zins C, Bouhours G, Lebigot J, Le Gall R, Bertrais S, et al. Benefit of the Vittel criteria to determine the need for whole body scanning in a severe trauma patient. Diagn Interv Imaging. 2012;93(5):371-9.

9. Hamada SR, Gauss T, Duchateau F-X, Truchot J, Harrois A, Raux M, et al. Evaluation of the performance of French physician-staffed emergency medical service in the triage of major trauma patients. J Trauma Acute Care Surg. 2014;76(6):1476-83

10. Cotte J, Courjon F, Beaume S, Prunet B, Bordes J, N'Guyen C, et al. Vittel criteria for severe trauma triage: characteristics of over-triage. Anaesth Crit Care Pain Med. 2016;35(2):87-92.

11. Sasser SM, Hunt RC, Faul M, Sugerman D, Pearson WS, Dulski T, et al. Guidelines for field triage of injured patients: recommendations of the National Expert Panel on field triage, 2011. MMWR Recomm Rep Morb Mortal Wkly Rep Recomm Rep. 2012;61(RR-1):1-20.

12. Moore L, Lavoie A, Abdous B, Le Sage N, Liberman M, Bergeron E, et al. Unification of the revised trauma score. J Trauma. 2006;61(3):718-22; discussion 722.

13. Copes WS, Champion HR, Sacco WJ, Lawnick MM, Keast SL, Bain LW. The injury severity score revisited: J trauma Inj infect. Crit Care. 1988;28(1):69-77.

14. Baker SP, O'Neill B, Haddon W, Long WB. The injury severity score: a method for describing patients with multiple injuries and evaluating emergency care. J Trauma. 1974;14(3):187-96.

15. Dick WF, Baskett PJ. Recommendations for uniform reporting of data following major trauma--the Utstein style. A report of a working party of the international trauma Anaesthesia and critical care society (ITACCS). Resuscitation. 1999:42(2):81-100.

16. Greenspan L, McLellan BA, Greig H. Abbreviated injury scale and injury severity score: a scoring chart. J Trauma. 1985;25(1):60-4.

17. DeLong ER, DeLong DM, Clarke-Pearson DL. Comparing the areas under two or more correlated receiver operating characteristic curves: a nonparametric approach. Biometrics. 1988:44(3):837-45.

18. Lerner EB, Shah MN, Cushman JT, Swor R, Guse CE, Brasel K, et al. Does mechanism of injury predict trauma center need? Prehosp Emerg Care. 2011;15(4):518-25.

19. Lerner EB, Shah MN, Swor RA, Cushman JT, Guse CE, Brasel K, et al. Comparison of the 1999 and 2006 trauma triage guidelines: where do patients go? Prehosp Emerg Care. 2011;15(1):12-7.

20. Brown JB, Stassen NA, Bankey PE, Sangosanya AT, Cheng JD, Gestring ML. Mechanism of injury and special consideration criteria still matter: an evaluation of the National Trauma Triage Protocol. J Trauma. 2011;70(1):3844 discussion 44-45.

21. Bouzat P, Ageron FX, Brun J, Levrat A, Berthet M, Rancurel E, et al. A regional trauma system to optimize the pre-hospital triage of trauma patients. Crit Care. 2015;19:111.

22. Kann SH, Hougaard K, Christensen EF. Evaluation of pre-hospital trauma triage criteria: a prospective study at a Danish level I trauma Centre. Acta Anaesthesiol Scand. 2007;51(9):1172-7.
23. Cox S, Smith K, Currell A, Harriss L, Barger B, Cameron P. Differentiation of confirmed major trauma patients and potential major trauma patients using pre-hospital trauma triage criteria. Injury. 2011;42(9):889-95.

24. Norcross ED, Ford DW, Cooper ME, Zone-Smith L, Byrne TK, Yarbrough DR. Application of American College of Surgeons' field triage guidelines by prehospital personnel. J Am Coll Surg. 1995;181(6):539-44.

25. Baxt WG, Jones $G$, Fortlage $D$. The trauma triage rule: a new, resource-based approach to the prehospital identification of major trauma victims. Ann Emerg Med. 1990;19(12):1401-6.

26. Champion HR, Sacco WJ, Copes WS, Gann DS, Gennarelli TA, Flanagan ME. A revision of the trauma score. J Trauma. 1989;29(5):623-9.

27. Sartorius D, Le Manach Y, David J-S, Rancurel E, Smail N, Thicoïpé M, et al. Mechanism, Glasgow coma scale, age, and arterial pressure (MGAP): a new simple prehospital triage score to predict mortality in trauma patients. Crit Care Med. 2010;38(3):831-7.

28. Jeong JH, Park YJ, Kim DH, Kim TY, Kang C, Lee SH, et al. The new trauma score (NTS): a modification of the revised trauma score for better trauma mortality prediction. BMC Surg. 2017;17(1):77.

29. Jr SMG, Massey M, Bouzat P, Vesselinov R, Levy MJ, Millin MG, et al. Correlation Between the Revised Trauma Score and Injury Severity Score: Implications for Prehospital Trauma Triage. Prehosp Emerg Care. 2019;23(2): 263-70.

30. Nordgarden T, Odland P, Guttormsen AB, Ugelvik KS. Undertriage of major trauma patients at a university hospital: a retrospective cohort study. Scand J Trauma Resusc Emerg Med. 2018;26(1):64.

31. Demetriades D, Sava J, Alo K, Newton E, Velmahos GC, Murray JA, et al. Old age as a criterion for trauma team activation. J Trauma. 2001;51(4):754-6; discussion 756-757.

32. Champion HR, Copes WS, Buyer D, Flanagan ME, Bain L, Sacco WJ. Major trauma in geriatric patients. Am J Public Health. 1989;79(9):1278-82.

33. Heffernan DS, Thakkar RK, Monaghan SF, Ravindran R, Adams CA, Kozloff $M S$, et al. Normal presenting vital signs are unreliable in geriatric blunt trauma victims. J Trauma. 2010;69(4):813-20.

34. Demetriades D, Karaiskakis M, Velmahos G, Alo K, Newton E, Murray J, et al. Effect on outcome of early intensive management of geriatric trauma patients. Br J Surg. 2002;89(10):1319-22.

35. Moss C, Cowden CS, Atterton LM, Arasaratnam MH, Fernandez AR, Evarts JS, et al. Accuracy of EMS trauma transport destination plans in North Carolina. Prehosp Emerg Care. 2015;19(1):53-60.

36. Gordon IJ, Sherwood Jones E. The right patient in the right place at the right time. QJM Int J Med. 2002;95(1):56-7.

\section{Publisher's Note}

Springer Nature remains neutral with regard to jurisdictional claims in published maps and institutional affiliations.

Ready to submit your research? Choose BMC and benefit from:

- fast, convenient online submission

- thorough peer review by experienced researchers in your field

- rapid publication on acceptance

- support for research data, including large and complex data types

- gold Open Access which fosters wider collaboration and increased citations

- maximum visibility for your research: over $100 \mathrm{M}$ website views per year

At $\mathrm{BMC}$, research is always in progress.

Learn more biomedcentral.com/submissions 